\title{
Cervical Lymphadenitis Due to Nodular Fasciitis in a Child
}

\author{
Kanik $\mathrm{A}^{1}$, Eliacik $\mathrm{K}^{2}$, Ince $\mathrm{T}^{3}$, Bayol $\mathrm{U}^{4}$, Helvaci $\mathrm{M}^{5}$
}

\begin{abstract}
Nodular fasciitis is a benign, reactive proliferation of fibroblasts in the subcutaneous tissues. It usually affects the trunk and upper extremities, and rarely the head and neck region of young adults. It is rare among children and the histologic findings may incorrectly suggest malignant lesions. We describe a two-year-old girl that referred to our clinic with complaints of fever and swelling on the right side of neck and diagnosed as lymphadenitis clinically. Cervical lymphadenitis due to nodular fasciitis is a rarity. We emphasize that nodular fasciitis needs to be included in the differential diagnoses of neck lymphadenitis during childhood.
\end{abstract}

Key words: Nodular fasciitis, Neck, Lymphadenitis, Childhood

\section{Introduction}

$\mathrm{N}$ odular fasciitis (NF) is a rare non-neoplastic soft tissue lesion mainly composed of myofibroblastic cells and fibroblasts. It is also known as subcutaneous pseudosarcomatous fibromatosis, inflammatory pseudotumor or proliferative fasciitis ${ }^{1}$. Although $10-15 \%$ of the cases have a history of trauma, most cases have no risk factors. In general, it is a rapidly growing self-limiting solitary lesion. The diameters of the lesions have been reported to be 0.5-10 $\mathrm{cm}$, most of them being smaller than $4 \mathrm{~cm}^{1}$. NF has been commonly seen in adults, with only $10 \%$ of the cases being children ${ }^{2,3}$. NF has been extensively seen in the trunk and upper extremities, but rarely in the head and neck region. Head and neck localization is more common in childhood than in adulthood ${ }^{4}$. NF is a self-limiting nonneoplastic soft tissue lesion, with no significant gender preference. The diagnosis must be histopathologically confirmed ${ }^{2}$. Excisional biopsy and surgical resection are curative ${ }^{3}$. In this paper, we present a pediatric case who admitted with symptoms of lymphadenitis and diagnosed as NF clinically and histopathologically.

\section{The Case}

A two-year-old girl referred to our clinic with complaints of fever and swelling on the right side of her neck. The fever and neck lump have started just a couple of days ago. The vital signs were normal except fever. Physical examination revealed a $4 \times 6 \mathrm{~cm}$ palpable packed lymph nodule on the right side of her neck.
'Dr. Ali Kanik', MD, Department of Paediatrics, ${ }^{2}$ Dr. Kayi Eliacik, MD, Department of Paediatrics, ${ }^{3}$ Dr. Tolga Ince, MD, Department of Paediatrics, ${ }^{4} \mathrm{Dr}$. Umit Bayol, MD, Associate Professor Department of Pathology, ${ }^{5}$ Dr. Mehmet Helvaci, MD, Associate Professor in Paediatrics. All from Tepecik Teaching and Research Hospital, Izmir, Turkey.

\section{Address for correspondence: \\ Dr. Kayı Eliaçık \\ E-mail: kayieliacik@gmail.com}

\section{How to cite}

Kanik A, Eliacik K, Ince T, Bayol U, Helvaci M. Cervical Lymphadenitis Due to Nodular Fasciitis in a Child. J Nepal Paediatr Soc 2014;34(2):141-143.

doi: http://dx.doi.org/10.3126/jnps.v34i2.9548

This work is licensed under a Creative Commons Attribution 3.0 License.

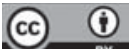

Other systemic examinations were within normal limits. Initial tests showed hemoglobin of $11.2 \mathrm{~g} / \mathrm{dl}$, leukocyte of $26,600 / \mathrm{cu} \mathrm{mm}$, and platelet of 4,53,000/ $\mathrm{cu} \mathrm{mm}$. Serum glucose, electrolytes, renal, hepatic function tests, and serum immunoglobulin levels were all within normal limits. Erythrocyte sedimentation rate was $75 \mathrm{~mm} / \mathrm{h}$, and C-reactive protein was $85 \mathrm{mg} / \mathrm{dl}$. Viral markers, serum markers for brucellosis and tuberculosis were negative. Nonspecific antibiotherapy (sulbactam-ampicillin) was tried, however the cervical lump was unresponsive to antibiotics. The ultrasonography examination showed a hypoechogenic and heterogenic mass at the right posterior 
cervical region. Magnetic resonance imaging (MRI) revealed $4 \times 6 \mathrm{~cm}$ packed contrast-enhanced lymph nodule on the right side of the neck (Fig. 1).

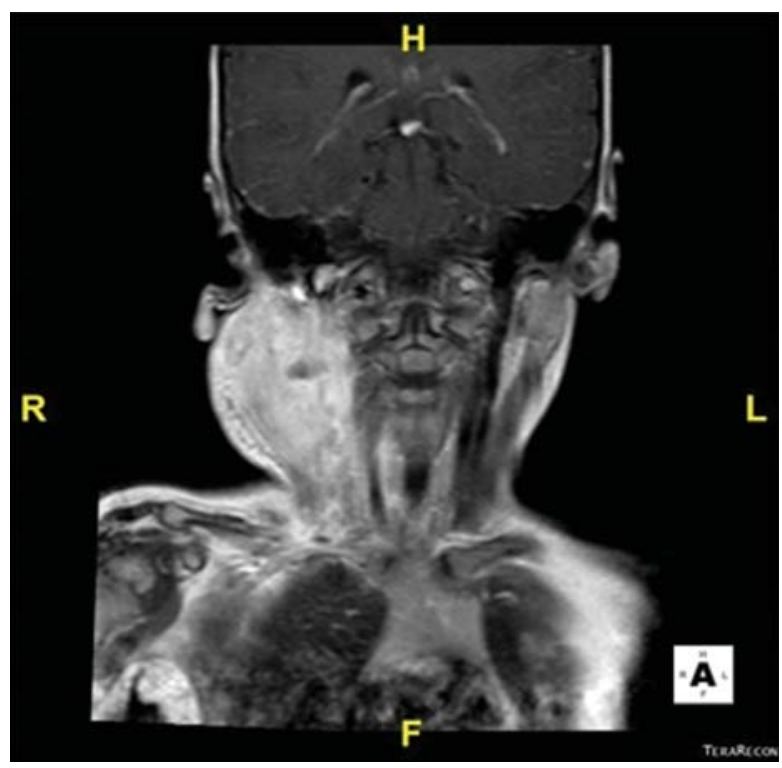

Fig 1: A $4 \times 6 \mathrm{~cm}$ conglomerate lymph nodule on the right side of the neck on MRI

During the follow-up, the lump continued to enlarge. Though total surgical excision was planned, because of the fixed mass with surrounding tissues, multiple core needle biopsies have been performed. The biopsy findings were consistent with NF. An inflammatory process consisting of vascular proliferation, mononuclear cells and fibroblastic proliferation was disrupting striated muscle and invading the lymph node (Fig. 2).

She received no specific therapies and the lump disappeared within a month. The case has been followed up for the past 30 months and there has been no evidence of recurrence.

\section{Discussion}

Lymphadenopathy is the pathology of the lymph nodes as regards dimension, number and consistency. Lymphadenomegaly may be the initial sign of a disease, or itself is the primary problem. The differential diagnoses of lymphadenomegaly comprise infections, malignancies, immunologic distorbencies, Castleman's disease (angiofollicular lymph node hyperplasia), sinus histiocytosis, and inflammatory pseudotumors.

Nodular fasciitis is a soft tissue lesion composed of proliferating fibroblasts. The lesion is described as pseudosarcomatous or proliferative fibromatosis, demonstrating an alarming nodular proliferation of fibroblasts. This designation is due to resemblance to sarcomas. It is a benign lesion, but it is sometimes mistaken for fibrosarcoma4.

Nodular fasciitis is not common during childhood, with the cases typically presenting with mass lesions in the head and neck region. Christina J. et al. ${ }^{5}$ found $39 \%$ of localization to be in the head and head neck region in an 18-case series of NF. Kim et al. ${ }^{6}$ have reported two cases (16-month-old and 11-year-old) with periorbital and supraclavicular, rapidly growing up to $4.6 \mathrm{~cm}$ and $3.5 \mathrm{~cm}$ masses, respectively. Though NF in the head and neck region is not very rare among the pediatric population, there is almost no cases presenting as cervical lymphadenitis in the English literature. Many NF cases may be overlooked due to uncertain clinic symptoms and histopathological findings ${ }^{1}$.

In NF, the lesion is typically submucosal, deeply oriented among the soft tissue compartments and wellcircumscribed. It is nodular and tender on palpation because of the strength of the bonds in submucosal tissue. It frequently grows rapidly without evidence of associated infection and may present histologic findings similar to those seen in malignant tumors,
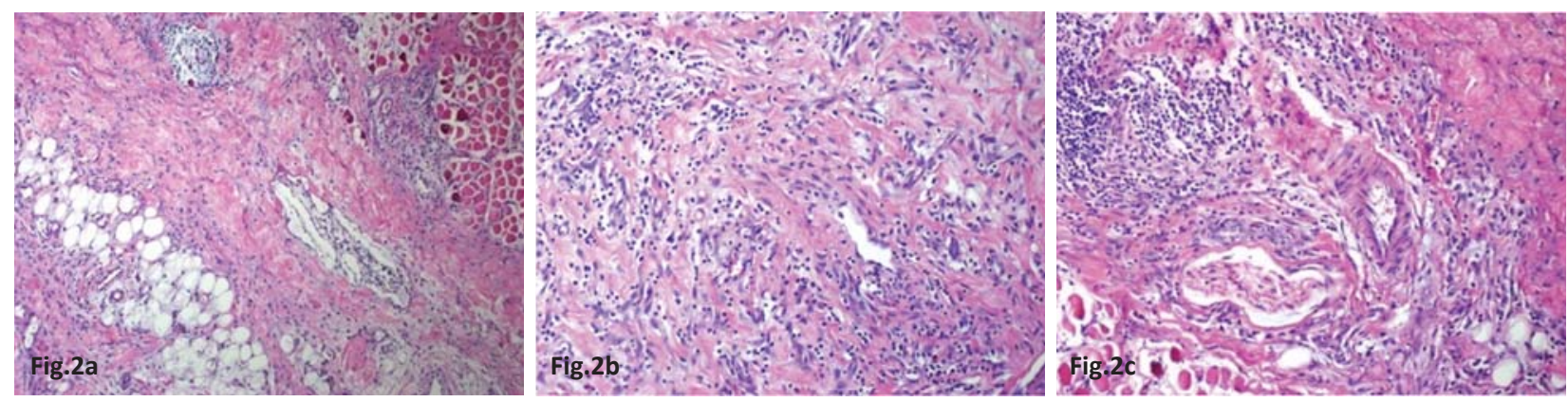

Fig 2: a. H\&E On the left, vascularly rich fibrous and inflammatory process disrupting striated muscle, b. Inflammatory process consisting of vascular proliferation, mononuclear cells and fibroblastic proliferation c. Inflammatory process entrapping lymphoid tissue. 
such as high cellularity, increased mitotic activity, and infiltrative growth pattern ${ }^{7}$. Ozben et al. ${ }^{7}$ reported a case of NF of the breast previously misdiagnosed as breast carcinoma. The key cytological features for diagnosis are plump, immature fibroblastic cells, chronic inflammatory cells, capillary proliferation, and vascular channels with extravasated red blood cells in an edematous myxoid background. There is mitotic activation, with no atypical cells. Immunohistochemical examination shows that spindle cells express vimentin and actin, but not desmin, keratin or S-100 proteins ${ }^{5,7}$. Rapid onset, chronic inflammation in the stroma, and the absence of atypia suggests that the lesion is benign ${ }^{8}$. In our case, vascularly rich fibrous and inflammatory process was disrupting striated muscle and involving the lymph node. Fibroblastic cells had oval and palestaining nuclei with no atypia. There were no atypical mitotic features (Fig 3).

Neither fine-needle aspiration cytology nor core needle biopsy can easily diagnose NF because it is difficult to obtain representative cells to make an accurate diagnosis using these techniques. The diagnosis usually requires the histopathological examination of an excisional biopsy ${ }^{7}$. An accurate histopathological diagnosis prevents an aggressive surgery. It has also been reported that the rest of the lesion disappeared spontaneously after the diagnostic biopsy $^{1}$. In our case, the lesion disappeared within a month.

\section{Conclusion}

We conclude that NF is a rare benign lesion during childhood. Lymphadenomegaly may be the initial presentation of NF, which should be included in the differential diagnosis of superficial and deep soft tissue masses of the neck, especially in recently developed rapidly growing masses.

\section{References}

1. Martínez-Blanco M, Bagán JV, Alba JR, Basterra J. Maxillofacial nodular fasciitis: a report of 3 cases. $J$ Oral Maxillofac Surg 2002;60(10):1211-4.

2. Yoo G, Baek SO, Jung SN, Kwon H, Moon SH, Shon WI. Nodular fasciitis in the forehead. J Craniofac Surg 2010;21(3):925-6.

3. Jang EJ, Park TI, Nam SC, Park JY. Nodular fasciitis in the submandibular gland. Diagn Cytopathol 2008;36(11): 805-8.

4. Somasundaram S, Murali K, Joseph S, Paul T. Nodular Fasciitis (Pseudosarcomatous Fibromatosis). Ind J Radiol Imag 2006;16:3:345-7.

5. Christina J, Bemrich-Stolz, Kelly DR, Muensterer OJ, Pressey JG. Single institution series of nodular fasciitis in children. J Pediatr Hematol Oncol 2010;32(5):354-7.

6. Kim ST, Kim HJ, Park SW, Baek CH, Byun HS, Kim YM. Nodular fasciitis in the head and neck: CT and MR imaging findings. Am J Neuroradiol 2005;26(10):2617-23.

7. Ozben V, Aydogan F, Karaca FC, Ilyan S, Uras C. Nodular fasciitis of the breast previously misdiagnosed as breast carcinoma. Breast Care 2009;4:401-2.

8. Eversole LR, Christensen R, Ficarra G, Pierleoni L, Sapp JP. Nodular fasciitis and solitary fibrous tumor of the oral region: tumors of fibroblast heterogeneity. Oral Surg Oral Med Oral Pathol Oral Radiol Endod 1999;87(4):471-6. 